\title{
El cuento en el Perú, 2015-2017
}

The Short Story in Peru, 2015-2017

\author{
Javier de Taboada Amat y León \\ Universidad Nacional Mayor de San Marcos, Lima, Perú \\ Universidad Peruana de Ciencias Aplicadas, Lima, Perú \\ Contacto: pchujtab@upc.edu.pe \\ https://orcid.org/0000-0002-8026-3817
}

\begin{abstract}
Resumen
El presente artículo hace una revisión de un conjunto de 30 libros de cuentos publicados en el Perú entre los años 2015 y 2017. Se atiende a las características de las ediciones, la organización de los contenidos, los temas más recurrentes y algunos motivos o metáforas que se repiten en varios de los libros.
\end{abstract}

Palabras clave: Cuento peruano; Premio Nacional de Literatura; Ediciones; Historia; Familia.

\begin{abstract}
The following article reviews a group of 30 short story collections published in Peru between 2015 and 2017. It takes into account the characteristics of the editions, the organization of contents, the most prevalent topics and some motifs or metaphors which recur in several of the collections.
\end{abstract}

Keywords: Peruvian short story; Literature National Prize; Editions; History; Family. 


\section{Punto de mira}

El año 2017, el Ministerio de Cultura del Perú convocó a la primera edición del Premio Nacional de Literatura. Según recordó el entonces ministro Salvador del Solar en la ceremonia de entrega del premio, se trata del retorno, después de más de tres décadas, de un reconocimiento histórico en las letras peruanas, que ha servido para distinguir a autores tan importantes en nuestra tradición como Martín Adán, Julio Ramón Ribeyro y Jorge Eduardo Eielson. Sin embargo, el retorno es más bien nominal, pues el anterior Premio Nacional de Literatura era un premio consagratorio y un reconocimiento a la trayectoria conjunta de un escritor $^{1}$, siguiendo el mismo cariz que tiene el premio, por ejemplo, en Chile o en Cuba. En cambio, el nuevo Premio Nacional de Literatura tiene carácter promocional y no consagratorio. Siguiendo el modelo de España y Paraguay, se ha optado por premiar libros publicados, práctica sin precedentes en el Perú; hasta ahora, los premios más importantes - como el COPE o el de la revista Caretas, para mencionar los más representativos en el género del cuento-, reconocen a manuscritos de cuentos individuales e inéditos, con el habitual procedimiento de la participación bajo seudónimo. El nuevo premio concibe al texto literario no solamente como creación de un autor individual, sino como parte de un circuito cultural, por eso se establece que sean las editoriales, indispensables y valiosas mediadoras entre el autor y el lector, quienes presenten los libros al concurso. En su primera edición, el certamen premió las categorías de Cuento, Poesía y Literatura Infantil y Juvenil, mientras que para el año 2018 se reconocerá a la Novela, la No Ficción y la Literatura en Lenguas Aborígenes.

Por designación de la Casa de la Literatura Peruana, tuve el honor de integrar el jurado en la categoría de Cuento, junto con otros distinguidos docentes y académicos. Cabe destacar que los mecanismos de designación de los jurados, en todas las categorías, se preocuparon de integrar la diversidad regional de nuestro país, ya que solamente algunos de los jurados residíamos en la capital, mientras que los restantes estaban ubicados en otras ciudades del país. El concurso supo aprovechar las posibilidades de la tecnología actual para reunir a personas de 
distintos lugares, pero que además provenían de distintas disciplinas, sin dejar de reconocer por cierto la creciente importancia de la mujer en todos los campos de la cultura. Se reunieron, pues, diversas miradas sobre la literatura y sus criterios de valoración, y aunque por momentos fue difícil la conciliación de perspectivas, el resultado fue enriquecedor.

En la categoría de Cuento se presentaron al concurso 26 libros editados entre 2015 y 2016. Esto no equivale a la totalidad de lo publicado en el género durante esos años, ya que, para empezar no se aceptaban reediciones ni antologías individuales ni colectivas; y además, debido a diversos factores, ya sea por desinformación, desinterés o desidia de algunas editoriales, algunos libros quedaron fuera del concurso. Sin embargo, es innegable que este conjunto abarca la gran parte de lo publicado y ofrece un panorama bastante completo y global de la práctica del cuento en el Perú. A partir de esta experiencia, y complementándola con algunos libros publicados en $2017^{2}$, quisiera intentar una descripción general del cuento en el Perú actual, e identificar ciertas líneas principales de desarrollo, así como algunos temas y motivos recurrentes en la producción de los cuentistas de nuestro país.

\section{Características de las ediciones}

Lo primero que habría que observar es que, si bien Lima mantiene su predominancia como centro cultural del país, también existe una interesante actividad editorial en otras regiones. De los 26 libros, 16 fueron publicados en la capital, 9 en diversas partes del Perú y 1 en el extranjero (Barcelona). En las regiones, Arequipa y Piura parecen disfrutar de un buen momento editorial, con 3 libros de cuentos cada una; también se registraron ediciones en Ica, Cusco y Juliaca. No es propiamente una sorpresa que Arequipa, ciudad con una larga y nutrida tradición literaria, aparezca en este puesto; en cambio, llama la atención el caso de Piura, por lo que futuras investigaciones, especialmente locales, deberían ofrecer más luces sobre el ambiente literario actual en dicha región. Aparentemente, la movida literaria en Piura no tiene todavía una industria editorial que la articule, pues dos de los tres 
libros son autoediciones, y el tercero, publicado por una universidad pública. En el caso de Arequipa, la editorial Aletheya publica a dos, y Surnumérica, al tercero.

Aletheya también es la editorial detrás del libro ganador en la categoría de Literatura Infantil y Juvenil, Taca Taca, de Gerónimo Chuquicaña. Según su director editorial Ruhuan Huarca, en sus 10 años de actividad la editorial ya ha logrado publicar más de un centenar de títulos. Surnumérica, por su parte, es el nuevo emprendimiento de Cascahuesos Editores, también con diez años de actividad y más de 60 títulos, y con intensa actividad no solamente en el sur del Perú, sino también en Ecuador. Dedicado ahora exclusivamente a la publicación de poesía, Surnumérica es su apuesta por la narrativa, y ha comenzado su actividad con 7 títulos. En Arequipa se nota entonces la integración vertical del negocio editorial, pues los escritores arequipeños publican en editoriales orientadas a atender esa demanda, y los libros son impresos en la ciudad. No ocurre lo mismo en otras ciudades, pues los libros editados en Ica y en Cusco, así como uno de los piuranos, han tenido que ser impresos en Lima, o incluso en Arequipa, en el caso del libro juliaqueño. Pese a ello, el Grupo Editorial Hijos de la Lluvia, de Juliaca, registra una actividad importante, con la publicación de libros de autores locales, en una lista que incluye algunos "consagrados", como Feliciano Padilla y Vladimir Herrera, y múltiples títulos de los directores de la editorial.

La autoedición es una práctica más común en las regiones, aunque también ocurre en la capital, donde se observaron dos libros editados por sus propios autores. En total, 6 de los libros presentados al concurso no encontraron o no consideraron necesario buscar un editor para proceder con la publicación. Indudablemente, la autoedición afecta la calidad del producto final, en cuanto al acabado de la impresión, el diseño gráfico de exteriores e interiores y la estética del ejemplar. Más aún, afecta las posibilidades de circulación de los textos, ya que fuera de circunstancias tan peculiares como las de un concurso nacional, tienen dificultades para trascender su ámbito más inmediato e ingresar a los canales habituales del circuito cultural, con una distribución que generalmente se realiza de mano en mano. Aún así, llama la atención que el tiraje más elevado, de todos los que consignan este dato en su pie de 
imprenta, corresponde a un libro autoeditado, Con cama adentro y otras travesuras, con 2000 ejemplares. Según indica su autor en la solapa, su libro anterior fue "un resonante éxito" y la edición se agotó "en menos de tres meses, en un recorrido del autor por los departamentos de San Martín, Loreto, Ucayali y Huánuco”. ¿Quiénes adquieren los ejemplares? ¿Qué tipo de eventos se organizan para promocionarlos? ¿Qué estrategias utilizan los demás autores autoeditados para distribuir sus libros? Todo ello requiere mayor investigación.

En contraparte, especialmente en Lima (y Arequipa), las editoriales independientes son las que dominan el mercado, al menos en el género del cuento que, como se sabe, se suele considerar con menor viabilidad comercial frente a la novela. Tanto Víctor Ruiz (2015) como Ricardo Sumalavia (2015) han apuntado la eclosión de editoriales independientes en el siglo XXI, aunque este último acota que el crecimiento de la industria editorial no necesariamente implica el crecimiento de la población lectora (Sumalavia, 2015, p. 9). De todos modos, resulta curioso, por lo menos, que de las grandes editoriales que operan en nuestro país — como Random House, Alfaguara, Planeta o Peisa—, solamente una de ellas se haga presente por sí misma en este conjunto, con La casa apartada (Alfaguara), y otra en una coedición (Peisa) ${ }^{3}$. Editoriales más pequeñas, pero que han sabido ganar presencia en el medio con su buen trabajo - como Animal de invierno, Campo Letrado, Borrador, Hipocampo o Altazor- son quienes han acometido la a veces riesgosa tarea de publicar géneros como cuento y poesía. Todas estas editoriales tienen un catálogo respetable, una línea más o menos definida del tipo de literatura que les interesa (algunas quizá con mayor claridad que otras), una buena presentación virtual y una variedad de servicios a ofrecer para futuros autores o instituciones. Algunas de ellas, especialmente las dos primeras, aspiran a tener proyección latinoamericana y por ello publican no solamente a autores peruanos, sino de otros países de la región e incluso europeos, en traducción. Es interesante, además, que en algún caso las editoriales puedan aliarse para llevar adelante una edición, como es el caso de La carne en el asador, publicada conjuntamente por Animal de invierno y Campo Letrado. Por otro lado, 
editoriales aún más pequeñas, como Torre de Papel, Apogeo y Maquinaciones Narrativas, tienen un catálogo más limitado —una media docena de títulos-y no ofrecen, excepto la primera, información clara sobre sus actividades.

La otra posibilidad es la publicación a cargo de instituciones privadas o públicas, solo concretada en este caso por la Universidad Nacional de Piura, la Universidad Esan y la Asociación Peruano Japonesa. Si bien es cierto que muchas universidades en el país cuentan con editoriales importantes, estas en muchos casos se encuentran vinculadas al ámbito académico y/o empresarial, y son contadas las que apuestan por la creación literaria. En tal sentido, El arte verdadero y otros cuentos es tanto la excepción como la confirmación de la regla, pues al hojear el catálogo de Esan, resalta como un extraño lunar en medio de libros de negocios. La Universidad Nacional de Piura no registra información sobre sus actividades editoriales en su página oficial ni en su organigrama, por lo que debe suponerse también que se trata de una situación excepcional. En cambio, la Asociación Peruano Japonesa (APJ) sí es conocida por su importante aporte editorial en diversos géneros literarios y en varios campos de la cultura, y si bien se suele privilegiar los textos que muestren vinculaciones de cualquier índole entre el Perú y el Japón, otras propuestas también alcanzan espacio para su difusión. Desde 1990, la APJ organiza un concurso para libros inéditos, alternando anualmente entre poesía y cuento, que se ha convertido en un referente importante en la escena literaria nacional. Además de un premio monetario, la publicación de la obra ganadora es uno de los atractivos del concurso. El libro ganador del Premio Nacional de Literatura en la categoría de Poesía, El hombre elefante y otros poemas, por ejemplo, fue publicado en este marco ${ }^{4}$.

Aunque no todas las ediciones consignan el tiraje en su página de créditos o en su pie de imprenta, la mayoría sí lo hacen. Este oscila entre los 500 y los 1000 ejemplares, lo que supone una leve mejora con respecto a los hábitos editoriales de fines del pasado siglo, cuando difícilmente una edición de un autor novato superaba el medio millar de ejemplares. Editoriales como Alfaguara, con una red asegurada de distribución, pueden aumentar el tiraje a 1500 ejemplares, 
y otras, más cautelosas, como Hijos de la Lluvia, prefieren no sobrepasar los 300 . Habría que complementar esta información con la de las ventas de los libros. ¿Qué títulos logran agotar su tiraje o incluso pueden demandar una reimpresión? ¿Cuántos ejemplares se entregan a los autores y qué otras condiciones se acuerda con ellos en cuanto al financiamiento de la edición, pago de regalías, etc.? La actividad editorial en el Perú requiere de mayor investigación.

\section{Organización del contenido}

Es de destacar que la mayoría de los textos presentados no son colecciones aleatorias de relatos, sino que son cuentarios, que aquí definiremos como un libro de cuentos con unidad temática evidente, persistencia de una voz narrativa y/o progresión entre las historias. Para empezar, los cuentarios guardan una unidad temática planteada de forma implícita o explícita. Esto último se expresa de manera más obvia cuando el texto organiza su índice en secciones según sus temas. Así procede Relámpago inmóvil, de Pedro Ugarte Valdivia, cuya primera sección, de homónimo título, agrupa relatos fantásticos vinculados a hechos históricos, mientras que en "Oficios y Artes" estos están vinculados a la práctica artística. En Tiro de gracia, de Marcelino Aparicio Jiménez, la primera sección está dedicada a la violencia política y la segunda presenta relatos sociales, amorosos y oníricos. Desde una mirada muy distinta de la literatura, Aspavientos, de Alejandro Susti, es una colección de microrrelatos en tres pequeños volúmenes sobre, respectivamente, temas políticos y culturales, relatos literarios y relatos sobre el amor.

En el caso de Detrás del velo el césped está verde, de María Jesús Floresta Vásquez Vélez, la división entre cuentos y cuentos para niños no logra verificarse en absoluto en los relatos, ni gráfica ni textualmente, y acaso responda a una estrategia comercial. Francamente increíble es el caso de un libro titulado Lecturas para la dirección cientifica en las organizaciones, de Adolfo Oswaldo Acevedo Borrego, cuyo paratexto, es decir, título, subtítulo y toda la organización del índice, incluyendo los títulos de los cuentos, proclaman a gritos su nopertenencia a la literatura. El texto está dividido en cuatro "Libros", el último de 
los cuales presenta una suerte de compendio de la historia del Perú. Solamente un lector extremadamente paciente ( $u$ otro interesado en los temas propuestos por el paratexto) podrá descubrir que las unidades que componen este índice son cuentos o relatos. Este libro fallido, que expulsa al lector literario para atraer a un supuesto lector "ejecutivo", es un interesante caso de cómo el paratexto puede llegar a anular el texto; y viceversa, pues el lector corporativo quedaría desconcertado e insatisfecho de no encontrar más que relatos sin ninguna guía de lectura ni moraleja claramente establecida.

Otro conjunto de cuentos proporciona, a través del título general y los títulos de los cuentos, una unidad temática evidente. Así, Bioficciones, de Benjamín Román Abram, presenta cuentos basados en personajes de la historia universal, y lo mismo hace, con un título más metafórico, Tránsitos, de Alfredo Dammert. Niños de otros mundos, de Roger Ildefonso, presenta, como su nombre lo indica, relatos esotéricos de niños extraterrestres. Extraños en el médano, de Santos Liborio Fiestas, recoge leyendas de la zona de Sechura. Con cama adentro y otras travesuras, de Darío Vásquez Saldaña, apela, desde el título, al humor erótico y al ambiente popular de la costa. Por último, El libro de nuestros nombres, de Walter Bedregal Paz, el más interesante de este grupo, presenta un “álbum familiar”, con una acertada combinación gráfica de fotografías antiguas con relatos breves inspirados en y que llevan el nombre de alguna persona de la familia del autor. La historia familiar, la genealogía de los nombres estructura el libro, así como en otros casos lo hace la historia universal o peruana.

En general, resultan más logradas las propuestas en donde, si bien existe una unidad interna entre los cuentos, esta debe ser inferida por el lector. En algunos casos, el paratexto proporciona una clave de lectura bastante clara, aun cuando los cuentos sean, a diferencia del grupo anterior, multidimensionales, y estén lejos de agotarse en una única posibilidad de lectura. Así, Tres mujeres, de Susan Noltenius, establece una estructura basada en el estado civil de sus protagonistas: divorciada, casada y soltera. Salvo el poder, de Ernesto Escobar Ulloa, construye, desde el título, y con ayuda de los títulos de los cuentos, sus 
temas articuladores: el poder, la política, la revolución. Siete paseos por la niebla, de Yeniva Fernández, establece, en cambio, su género y su atmósfera: el fantástico clásico. En el mismo sentido, La casa apartada, de Antonio Gálvez Ronceros, apunta al ámbito rural como el espacio en donde se desenvuelven los relatos. Ciudades vencidas, de Miguel Sánchez Flores, plantea también en su título uno de los motivos principales del libro; sin embargo, los títulos de los cuentos van por otro lado y ni siquiera se listan en un índice.

Nada de ello implica que la simple colección de cuentos sea ontológicamente inferior al cuentario. Por un lado, quizás es tarea del crítico encontrar las conexiones no tan evidentes entre relatos a primera vista diversos. Desde nuestro particular punto de vista, libros como El arte verdadero, de Jorge Ninapayta; Las visitaciones, de Pedro Llosa; La carne en el asador, de Miguel Ruiz o Sonata para un hombre lejano, de Yuri Vásquez guardan una coherencia interna. Por otro lado, esa misma heterogeneidad puede ser un mérito cuando el autor, como lo hace, por ejemplo, Hechizo, de José Castro Urioste, demuestra su versatilidad en un conjunto de relatos de diversa extensión, temática y ubicación espacio-temporal. En tal caso, la propia administración de los recursos narrativos y el acierto en el manejo del suspenso y el giro resulta un factor unificador de los cuentos.

\section{Temas}

La historia parece ser uno de los temas y discursos que más atrae la atención de los cuentistas peruanos. Algunos toman como inspiración a la Historia con mayúsculas, monumental, esa historia compuesta de grandes personajes y eventos claves. Otros se ocupan menos de las grandes figuras históricas como de contextos específicos que determinan la vida de personajes ficcionales.

Tres libros de cuentos recrean, total o parcialmente, la vida de figuras o eventos históricos significativos. La colección de personajes que presentan, claramente identificables desde el índice o levemente disimulados en el título, oscila entre gobernantes y exploradores de la historia universal (Napoleón Bonaparte se repite en los tres libros, y Neil Armstrong en dos de ellos); 
personajes de la historia del Perú (que son los menos, pero Atahualpa también aparece por partida doble); científicos (Einstein es la figura inevitable); escritores o artistas (Bram Stoker, la única coincidencia) y figuras míticas o ficcionales (Don Quijote se duplica). En Tránsitos, Alfredo Dammert elige detenerse en una escena histórica, ya sea célebre o que permita sintetizar la vida del personaje. La literatura ilustra la historia, la hace más atractiva. En cambio, en Bioficciones de Benjamín Román la historia es un punto de partida muy básico para dispararse, sobre todo, hacia la ciencia-ficción. Más que dejarse fascinar por la historia, lo que hace es aprovechar esa fascinación de muchos lectores para dar rienda suelta a su imaginación. Incluye un índice de personajes para facilitar a los lectores su búsqueda. Finalmente, Relámpago inmóvil, de Pedro Ugarte Valdivia, el más logrado de los tres, no opta, como los anteriores, por una profusión de figuras, sino que elige algunos eventos históricos (los atentados del 11M en Madrid, las misiones jesuitas en la selva cusqueña) o personajes (Sara Ellen, Niccolo Paganini) para plantear, en la primera parte, otras posibilidades alternas del tiempo, especialmente su congelamiento; $y$, en la segunda, cuestiones estéticas, especialmente la fascinación que ejerce la obra de arte.

Otros cuatro libros se aproximan a la historia de manera más refractaria, entendiéndola como un contexto que determina la vida de personajes ficticios. La gente común, más que las grandes figuras, es la que puebla las historias. Además, no todos los cuentos son históricos o presentan una contextualización específica; algunos cuentos de cada libro pueden usar una contextualización más genérica, sobre todo para presentar asuntos de pareja o familiares. Salvo el poder, de Ernesto Escobar, mantiene algo de la fascinación por algunas figuras históricas importantes y que de algún modo podrían asociarse con la izquierda y su idea de revolución (Cristo, Mao, Abimael, Che Guevara y Alejandro Toledo) para ensayar con ellos juegos de desenmascaramiento, teorías conspirativas, ucronías y aguafuertes. Al mismo tiempo, mantiene el otro ojo en lo cotidiano con un mapeo de los más diversos estratos sociales. Hechizo, de José Castro Urioste, presenta una atracción por la guerra de los Balcanes ("Sasha"), pero también 
por los paralelos entre la Conquista europea América Latina y la inmigración latinoamericana a Europa en tiempos más recientes ("Muertes circulares"); o entre las dictaduras del cono sur y la democracia vigilada americana post-11/9 ("Hyde Park"); sin olvidar, en el contexto peruano, la crisis económica de los 80 y la consiguiente ola inmigratoria a los EE. UU ("La llamada"). Ciudades vencidas, de Miguel Sánchez Flores, aprovecha el terremoto de Pisco de 2007 para desprenderle destellos irónicos ("El Couple Riding de Kandinsky"), pero también recuerda en otros cuentos la inmigración peruana a EE. UU. y la Segunda Guerra Mundial, siendo estos últimos los eventos históricos más recurrentes en el conjunto de los textos. Precisamente, el cuento "El japonés Fukuhara", que da título al libro de Selenco Vega, habla de la discriminación a los japoneses en el Perú durante la Segunda Guerra Mundial, momento oscuro y silenciado de nuestra historia, enlazándolo hábilmente con el ascenso y caída de Fujimori, así como con la violencia política en la sierra.

La violencia política es un capítulo aparte en la historia nacional que no presupone un interés general por esta, ya que es un suceso fundacional de la sociedad peruana contemporánea, además de ser un tema que ha tenido razonable éxito en el mercado editorial. Cuatro de los libros revisados se aproximan consistentemente a este tema, que también reverbera fugazmente en muchos otros relatos donde no llega a ser el asunto central. Tal parece que el tema está aún lejos de agotarse. Salvo el poder, de Ernesto Escobar, aprovecha el contexto de la izquierda revolucionaria ya mencionado en el párrafo anterior (dentro del cual coloca a Abimael Guzmán como un aprendiz megalómano de Mao, humillado por este en su encuentro - ficticio - en China, en "La insignia de Mao") para visitar algunos momentos y espacios claves del proceso, como la matanza de los penales (“1986”) y la ciudad de Huanta (“Juegos Olímpicos”). Tiro de gracia, de Marcelino Aparicio, presenta diversas anécdotas recogidas desde su labor de periodista, relatos truculentos, vinculados a prácticas de abusos militares. En Nada especial, de Goyo Torres, se recuerda la efervescencia política en las aulas universitarias y las detenciones arbitrarias de las fuerzas del orden ("Buenos 
deseos"), pero también se reflexiona, con inteligencia, sobre cómo la polarización de la guerra sirvió para incitar pasiones y rencores personales, de pobladores que denunciaban a un lado o al otro a sus rivales por razones de codicia, venganza o rivalidad entre poblados (“¡Hierbasanta, hierbasanta!”). Finalmente, La carne en el asador, de Miguel Ruiz, incluye un relato, verdaderamente ingenioso y agudo, sobre un sujeto que monta una empresa encargada de realizar reparaciones rápidas luego de los atentados dinamiteros en la capital (“Simbiosis"), así como también un cuento que rescata la práctica del retablo ayacuchano como medio idóneo para la representación del conflicto ("Una estrella para cada niño").

Más interesados en lo social contemporáneo que en lo histórico se encuentran La casa apartada, de Antonio Gálvez Ronceros y El arte verdadero, de Jorge Ninapayta de la Rosa. En el primero se retrata un mundo rural que quizás sea el de hace unas décadas o el que aún se está desvaneciendo, en el que destacan sus estrategias de supervivencia (“¿Recuerdas?”), sus relaciones con la cultura letrada ("Lecturas iletradas"), con las creencias populares esotéricas ("La casa apartada", "Jacinto y Manfreda"), sin dejar de ahondar en las profundidades de la codicia y el crimen ("La madrugada triste"). El humor fino permea el libro, que además hace gala de algunas técnicas narrativas virtuosas, pero que restan algo de naturalidad a los relatos. El arte verdadero comparte el humor, aunque en este caso es un humor algo más grueso, cercano a lo "chicha". Se pone en escena, desde esta perspectiva popular e irreverente, algunos de los discursos predominantes en el actual escenario social, como el de la moda ("Que sigan los éxitos"), el espectáculo ("El arte verdadero"), la gastronomía ("Pan francés"), el emprendedurismo y la motivación (“Muy agradecido") y la música ("Hechicera”).

"La verdadera patria de todo hombre es su infancia", escribió Rilke. En lugar de instalarse como testigos de su tiempo —o de tiempos diversos-, otros escritores optan por la historia personal antes que la historia social, sin olvidar que la primera puede ser siempre una metonimia de la segunda. A veces se emplea la vieja pero siempre renovadora fórmula de acercarse con la mirada inocente del niño al microcosmos de poder que es la familia; otros prefieren detenerse en los 
impulsos contradictorios e insatisfechos de la adolescencia, impulsos eróticos, pero también creativos (los escarceos de la vocación literaria) o tanáticos. Casi siempre se somete a un juicio implacable a las figuras del panteón familiar: madre, padre, hermanos, abuelos; sin embargo, también hay momentos de redención y reconciliación. Menos frecuente es que el narrador asuma la figura del padre o la madre, aunque ocurre en algunas ocasiones.

¿Qué tengo de malo?, de María José Caro es el cuentario más consistentemente instalado en la infancia y su lento pero inexorable transcurrir hacia la pubertad. Parte, en el cuento de apertura, de la ruptura de la familia ${ }^{6}$ y la muerte simbólica del padre (“Árbol de Navidad") para luego interrogar a las figuras del núcleo familiar, así como también los espacios de socialización secundaria, como el colegio y el vecindario, para, hacia el final, lidiar con las sutilezas de la amistad y con las complicadas relaciones con el sexo opuesto. Otros libros, como Una calma aparente, de Christian Solano; Aqui no hay icebergs, de Katya Adaui y El japonés Fukuhara, de Selenco Vega también abordan la infancia y la familia, pero alternándolas con otras problemáticas más adultas.

La generación anterior, la de los abuelos, representa la conexión con un pasado más remoto, como el de las guerras mundiales (Adaui, "Todo lo que tengo lo llevo conmigo") o la guerra del 41 con Ecuador (Caro, "Pasajeros") y al mismo tiempo, su clausura, pues la muerte del abuelo/a, es como dice Adaui, "la primera pérdida" (2017, p. 24), la primera experiencia de la muerte y con ella el cierre de un tiempo lejano y de viejas rencillas. Por otro lado, en tiempos de familias quebradas, que ya no responden al modelo nuclear mamá-papá, la abuela puede aparecer como cuidadora negligente, bajo cuyas narices se cometen incluso abusos sexuales (Adaui, "Este es el hombre"); o por el contrario, como figura poderosa - patriarcal diríase —, que gobierna incluso a la distancia y sin cuya presencia no se puede siquiera enterrar a los muertos (Vega, "Esperando a la abuela").

La relación entre hermanos generalmente se muestra como una de 
protección y solidaridad. Cuando son niños establecen una complicidad contra los padres (Caro, "A mitad de la noche"; Adaui, "Todo lo que tengo lo llevo conmigo") y un vínculo que a veces persiste inalterable hasta la muerte (Adaui, "Los gemelos Hamberes") pero que también se complica, sin llegar a envenenarse, con la incorporación de la familia política (Adaui, "Si algo nos pasa") o por dinámicas perversas de la culpa y el éxito (Vega, "Dos hermanos").

Por cierto que las figuras centrales de la familia son el padre y la madre. Sobre el primero, además, se puede recordar que varias novelas publicadas en la década presente han sido calificadas como "novelas del padre", y sin duda, es una figura de importancia también en la narrativa corta. Además de los libros mencionados, otros como Las visitaciones, de Pedro Llosa y Bitácora del último de los veleros, de Orlando Mazeyra indagan en la figura paterna. En muchos casos el padre es presentado bajo una luz negativa, ya sea estragado por el alcoholismo (Caro, “Árbol de Navidad"; Mazeyra, "Espejo roto", "Feriado de octubre”, entre otros), el deterioro físico y mental (Caro, "Las palabras") o directamente el suicidio (Adaui, “Agapornis”). Su carácter está marcado por un autoritarismo que llega a la agresión física y verbal (Mazeyra, "Espejo roto") o por una carencia de afecto (Adaui, "Todo lo que tengo lo llevo conmigo"). Cuando el padre es reemplazado por el padrastro, las relaciones se encaminan a la perversión (Solano, "Familia"). Es cierto que también hay momentos de complicidad, sobre todo en las relaciones padre-hija, pero esa admiración suele terminar en una decepción (Caro, "Zancos"; Adaui, "Todo lo que tengo lo llevo conmigo"). Sin embargo, también hay cuentos que buscan una visión más global y balanceada del padre (Mazeyra, "Mi viejo"; Vega, "El japonés Fukuhara") o incluso elogiosa (Llosa, "El olvido que seremos").

La madre también es sometida a juicio, en ocasiones de manera tan desfavorable como el padre (Solano, "Familia"; Vega, "Esperando a la abuela"), pero en general de forma más equilibrada. La relación de madre e hija no es menos compleja que la de padre e hijo, y es diseccionada en algunos cuentos de escritoras, que junto a la frivolidad o frialdad de la madre pueden percibir también 
su profundo amor y tentar la reconciliación (Caro, "Las palabras"; Adaui, "Todo lo que tengo lo llevo conmigo"), aunque esta a veces se derrape por los filos de la ironía, que dificulta la comunicación real (Adaui, "Siete olas"). En otros casos, la maternidad no es juzgada, sino que es (parte de) la posición de enunciación del relato; así, en Tres mujeres, de Susan Noltenius, se exploran las dificultades de la adolescencia de los hijos y las expectativas sociales sobre el rol de madre, demandadas, por ejemplo, groseramente por el exmarido ("Divorciada"), pero que forman parte de una red de estereotipos que dificultan la movilidad de la mujer que ha decidido trabajar y ser madre a la vez.

Casi todos los libros mencionados hasta el momento en esta sección comparten una estética realista, predominante en la historia y la práctica de la literatura peruana. Sin embargo, hay que destacar también algunas propuestas que se apartan de la representación mimética y/o de la lógica causal. Siete paseos por la niebla, de Yeniva Fernández y Sonata para un hombre lejano, de Yuri Vásquez, se acercan al fantástico clásico. Por su parte, Aspavientos, de Alejandro Susti y Al fin, el hombre bala de Pedro Pérez del Solar son próximos a la metaficción y al microrrelato.

En Sonata para un hombre lejano, todavía algunos cuentos se mantienen dentro del realismo, aunque la técnica narrativa permite conexiones entre temporalidades ("Una vez un descuido"), u ofrece un contrapunto mítico a una historia de cotidiana sordidez ("Entre el mito, el amor y la lluvia"). Algunos mantienen cierta ambigüedad entre una lectura realista y otra fantástica ("Sonata para un hombre lejano"). Otros, en cambio, entran de lleno en lo fantástico, ya sea por la distorsión del tiempo y el espacio ("Un día en un laberinto de cosas raras"), por ingresar en un mundo carnavalizado ("La fiesta del Sol”), o por recoger motivos clásicos del ámbito fantástico, como el libro mágico ("El libro de los siglos") o la mujer-gata ("La gata griega"). Este motivo de la metamorfosis de mujer a gata o de gata a mujer se repite en Siete paseos por la niebla ("Persona desaparecida", "Antes que caiga la noche"). En tiempos animalistas (los escenarios de este último cuento son paraísos gatunos urbanos, como el parque 
Kennedy de Miraflores), el animal doméstico más misterioso y sensual recobra su poder. Por lo demás, este cuentario se instala consistentemente en el género fantástico, apelando a otros motivos clásicos, como la vampiresa ("Rutka o la historia de algunas flores extrañas"), el diablillo ("La pequeña compañía") o la reencarnación ("En memoria de Evelina”) y creando también algunos novedosos, como la personificación de la neblina limeña ("Con Yolanda en el acantilado"), pero en todos los casos adoptando una mirada femenina que desestabiliza los presupuestos falocéntricos del género y lo renueva en forma inquietante. Los relatos generalmente comienzan en media res, progresando de la naturalidad a la sorpresa (con la irrupción de lo fantástico) y de esta al desenlace concluyente.

Nos dice Enrique Prochaska en el prólogo de Aspavientos: "El lector apenas encontrará historias en estas historias: se tratan más bien de la sustancia de la observación [...]" (en Susti, 2016, t. I, p. 14) y lo mismo podría aplicarse al libro de Pérez del Solar. El microrrelato, más que encapsular una anécdota, lo que busca es generar un efecto de sentido, y aunque los relatos puedan extenderse a unas pocas páginas, permanecen impermeables a las expectativas convencionales. Más que un universo extraño, como en los casos anteriores, lo que este par de libros presenta es una mirada extraña, rarificadora si cabe el término, que puede presentar lo cotidiano como horroroso, risible, cruel o sobrecogedor. Aspavientos aprovecha su división en tres pequeños volúmenes independientes, así como el acompañamiento gráfico de Mario Molina, para presentar pequeños universos en donde se parodia los absurdos kafkianos de la ley y los distintos registros del discurso oficial (volumen I), las pretensiones de la literatura y las artes, especialmente en su enseñanza, transmisión y conservación (volumen II) y las relaciones de pareja (volumen III). La metaficción, es decir, la reflexión sobre la propia construcción de la ficción y sobre el quehacer literario recorre los tres volúmenes. Al fin, el hombre bala no presenta una estructura definida, y la extensión de los cuentos oscila entre un párrafo y una decena de páginas (los más extensos, como los que veremos en la siguiente sección, son los que más se acercan a lo convencional), pero comparte esa mirada peculiar que puede alienar 
algo tan simple y cotidiano como el maquillaje ("No me mires, no me mires...") o el mero transcurrir del tiempo ("De dos a dos y media"), por poner un ejemplo. En otros casos, con el procedimiento inverso, se naturaliza lo extraño, como la muerte ("Próximo estreno") o el monstruo ("Desayuno en Binghantom"). Más que a la parodia, en este caso los relatos se acercan al absurdo o al sinsentido.

\section{Motivos}

Para finalizar, quisiera llamar la atención sobre dos escenas que se repiten en diferentes libros y que podríamos entender, acaso, como metáforas que logran concretizar algún anhelo o angustia flotante en nuestro imaginario social. Una es la escena del hombre que vuela; la otra, la del cruce riesgoso o suicida.

Tres cuentos de distintos autores narran la historia de un hombre que intenta volar y, en cierta manera, lo logra. "Todo es relativo" de Jorge Ninapayta, es la historia de Rumildo, quien descubrió su vocación auténtica — volar — tras dedicarse, sin éxito, a distintas actividades artísticas, como la poesía, el canto, la fotografía y la pintura con aerosol, y quien, tras muchos ensayos, llega a presentar su acto culminante ante la presencia de un puñado de amigos. "Volar" consiste aquí en quedarse suspendido en el aire, inmóvil, desafiando la ley de la gravedad por algunos largos segundos o minutos antes de la inevitable caída. "Al fin, el hombre bala", relato que da título al libro de Pedro Pérez del Solar, narra la historia del dueño de un circo, quien para rescatarlo de la crisis en que lo dejó la irrupción armada de subversivos que interrumpieron la función y quemaron el vestuario y la utilería, se le ocurre montar un número del hombre bala; sin embargo, el acróbata encargado de ejecutarlo no aparece y él mismo tiene que asumir su papel en el cañón: volar consiste en trazar una elipse impelido por la fuerza de la pólvora. "El ángel loco", de Goyo Torres, narra la historia de un joven que llega a un pueblo, dice ser un ángel y poder volar, pero nadie lo toma en serio y se convierte en el loco del pueblo hasta que un día, durante una emergencia provocada por un huayco, después de una orden del alcalde, emprende el vuelo. Volar es equivalente aquí al movimiento de los pájaros en el cielo.

En el primer caso, volar es el perfeccionamiento de un arte, animado 
"por una intención de fundamento tripartita: un poco para ayudar a la ciencia y a toda la humanidad, otro poco para hacerse famoso, y otro más por si conseguía mejorar su situación y quién sabe si convertirse en ricachón y todo lo demás" (Ninapayta, 2015, p. 106). El segundo de estos objetivos es el que se cumple, irónicamente, porque la cantidad de fracturas obtenidas de su vuelo final lo vuelve una curiosidad - casi celebridad- médica. En el segundo cuento, volar es lo que permite la supervivencia del arte, ya que no presentar el número "era el fin: el temido momento de desbandar el circo" (Pérez del Solar, 2016, p. 18). La improvisación culmina con la explosión del cañón, aunque no es del todo claro lo que pasa después:

[...] la explosión conmocionó tanto a los espectadores que, después de ser calados por ese relámpago de carne hecha chispas, después de una interminable ronda de aplausos que hizo sangrar más de una mano, es decir, cuando por fin recuperaron la plena conciencia, todo se llenó de gritos de padres buscando a sus hijos, niños corriendo en círculos, llorando a todo pulmón, extendiendo los brazos al aire. (Pérez del Solar, 2016, p. 26)

En ambos cuentos la vinculación con lo nacional se hace explícita con la mención de las Fiestas Patrias. En el último cuento, la capacidad — que no acto, como en los dos anteriores - de volar es posibilitada por una pócima mágica. A diferencia de los performers que con el acto de volar buscan realizar una aspiración, en "El ángel loco" la posibilidad de volar es interdicta directamente por la autoridad (interdicción que como vimos es levantada al final):

El alcalde comunal dijo estar cansado de tanto loco, timador, mercachifles y vendedores de cebo de culebra que llegaban al poblado y aconsejó a hombres y mujeres no dejarse embaucar por el sujeto.

Y tú — señaló con sorna al muchacho- no vueles. Puedes asustar a la gente. (Torres, 2016, p. 50)

¿Qué significa entonces esta metáfora del vuelo? Jorge Ninapayta se toma la molestia de explicarlo:

Cuando se tomaba sus aguas en La Copa Rota y quedaba a merced de la nostalgia, trataba de explicarlo con muchas imágenes y multitud 
de palabras largas que en el fondo significaban que había deseado elevarse por encima de la pobreza, por sobre ese barrio miserable de Cinco Esquinas, adonde llegó a vivir al comienzo. (Ninapayta de la Rosa, 2015, p. 106)

Lo mismo, mutatis mutandis, puede aplicarse a los otros dos cuentos.

La escena del cruce suicida se repite también en tres cuentos. "Muertes circulares", de José Castro Urioste hace un contrapunto entre la época de la Conquista y la contemporánea, un paralelo entre el trato inhumano otorgado por los españoles a los indígenas durante la invasión de América, y el no menos inhumano que reciben algunos inmigrantes latinoamericanos en España en nuestros días. Los tiempos se conectan a través de una apuesta crudelísima y brutal, victimarios que apuestan por la supervivencia (o no) de sus víctimas. El capitán Alvarado y sus hombres arrojan una lanza a una india sobre un caballo con sus tres hijos a ver si alguno de ellos sobrevive; mientras que unos jóvenes españoles obligan a un peruano y un ecuatoriano a cruzar los cuatro carriles de una autopista con vehículos a ciento veinte kilómetros por hora. "Cruzar la autopista", de Pedro Pérez del Solar, cuenta la historia de unos jóvenes quienes, luego de la destrucción de un puente peatonal por un camión irresponsable, se ven obligados a cruzar la Panamericana; tienen que sortear así los vehículos, y, además, cargar a uno del grupo que se resiste a cruzar, pero que se hace necesario para los demás, para llegar a los mejores locales de diversión nocturna. "Una vez un descuido", de Yuri Vásquez, también establece un contrapunto entre dos temporalidades, pero no históricas, sino dos momentos en la vida de los personajes; esta sufre un cambio radical cuando la hija de la pareja, que se ha quedado sola en el nido porque su padre estaba embebido en un videojuego, sale corriendo a la pista a buscar un auto que creía el de su papá, y es atropellada, quedando minusválida.

La autopista o vía expresa es por supuesto uno de los emblemas de la modernidad, útil para ahorrar el tiempo, siempre limitado, de los conductores; es decir, de quienes tienen el poder económico de poseer un vehículo particular, pues muchas autopistas no están abiertas al transporte público. Para quienes están excluidos de ese entorno, sobre todo para los sufridos peatones, la autopista no es 
más que un símbolo, a veces fascinante (recordemos la contemplación hipnótica del tráfico de Lucas desde el puente peatonal en "Cruzar la autopista") pero sobre todo peligroso, potencialmente mortal. La autopista es una muralla de bólidos que divide irremisiblemente sus dos extremos, y las costumbres salvajes de la jungla urbana, tanto la deliberada crueldad como la negligencia lindante con lo criminal rompen los accesos y puentes o impelen a arriesgar la vida de los desfavorecidos, ya sean inmigrantes pobres o niños desatendidos.

En conclusión, vemos que el cuento en el Perú atraviesa un buen momento, con una variedad temática y estética que enriquece, sin duda, el panorama de nuestra actual narrativa, y que no se agota, en absoluto, en lo dicho aquí por tres razones. Primero, varios de los libros revisados podrían funcionar en distintas categorías y no solo en aquella donde los hemos encasillado para hacer más manejable el conjunto. Segundo, hay otros temas, incluso ya señalados en las antologías de Víctor Ruiz y Ricardo Sumalavia, como la autorreferencialidad o autoficción, el exilio y la representación de la ciudad, que no hemos podido desarrollar aquí. Tercero, hay muchos autores valiosos que no hemos revisado por la acotación temporal que hemos elegido ${ }^{7}$, pero que se encuentran en plena producción y forman parte de la escena literaria contemporánea. El balance definitivo del cuento peruano en las dos primeras décadas del siglo XXI aún está por hacerse, pero cuando alguien se atreva a emprender tal empresa, este trabajo, junto con otros, podrá servirle como una preliminar orientación.

\section{Notas}

1 En realidad, el Premio Nacional de Literatura era un capítulo del Premio Nacional de Cultura. Este último fue reinstituido desde 2012 por el Ministerio de Cultura en tres categorías: trayectoria, creatividad y buenas prácticas institucionales. Cada año se premia a un sector de la cultura nacional. En literatura han recibido el galardón, durante el presente siglo, Edgardo Rivera Martínez, Rodolfo Hinostroza y Carlos Germán Belli.

2 Consideraré cuatro libros que han tenido buena recepción crítica en 2017: Katya Adaui, Aquí hay icebergs; Selenco Vega, El japonés Fukuhara; Christian Solano, Una calma aparente; María José Caro, ¿Qué tengo de malo?

3 Si se observan los cuatro libros de 2017, aparece también Random House (Aquí hay icebergs) y nuevamente Alfaguara (¿Qué tengo de malo?). 
4 Asimismo, los libros de cuentos Las visitaciones, mención honrosa en el Premio Nacional, y El japonés Fukuhara, libro destacado de 2017.

5 Un botón de muestra: "Libro I. Institucionalidad y paradigmas de decisión. Para entender la manera de resolver problemas".

6 Escenas de ruptura familiar aparecen también en Solano, "Familia" y Adaui, "Todo lo que tengo lo llevo conmigo".

7 Entre ellos, cabe mencionar a Carlos Yushimito, Daniel Alarcón, Juan Manuel Robles, Sergio Galarza, Francisco Ángeles, Diego Trelles, Jennifer Thorndike, Luis Hernán Castañeda, Johann Page, Miguel Ángel Torres Vitolas, Dante Trujillo, Juan Manuel Chávez, Alexis Iparraguirre, Sandro Bossio, Karina Pacheco, y un largo etcétera.

\section{Referencias bibliográficas}

Acevedo Borrego, A. (2016). Lecturas para la dirección cientifica en las organizaciones. Lima: Edición del autor.

Adaui, K. (2017). Aqui hay icebergs. Lima, Random House.

Aparicio Jiménez, M. (2015). Tiro de gracia. Piura, Edición del autor.

Bedregal Paz, W. (2016). El libro de nuestros nombres. Juliaca, Grupo Editorial Hijos de la Lluvia.

Caro, M. J. (2017). ¿Qué tengo de malo? Lima, Alfaguara.

Castro Urioste, J. (2015). Hechizo. Lima, Hipocampo Editores.

Dammert Lira, A. (2015). Tránsitos. Lima, Maquinaciones narrativa.

Escobar Ulloa, E. (2015). Salvo el poder. Barcelona, Editorial Comba.

Fernández, Y. (2015). Siete paseos por la niebla. Lima, Campo Letrado.

Gálvez Ronceros, A. (2016). La casa apartada. Lima, Alfaguara.

Ildefonso Huanca, R. (2016). Niños de otros mundos. Lima, Edición del autor.

Liborio Fiestas, S. (2015). Extraños en el médano. Piura, Edición del autor.

Llosa, P. (2015). Las visitaciones. Lima, Fondo Editorial Asociación Peruano Japonesa. 